\title{
FINANCIAMENTO E GASTO PÚBLICO DA EDUCAÇÃO BÁSICA NO BRASIL E COMPARAÇÕES COM ALGUNS PAİ́SES DA OCDE E AMÉRICA LATINA
}

\author{
Jorge ABrahão
}

\begin{abstract}
RESUMO: $\mathrm{O}$ artigo aborda o financiamento e gasto público voltados à educação básica no Brasil e de alguns países da Organização de Cooperação para o Desenvolvimento Econômico (OCDE) e América Latina, de forma a se ter um quadro comparativo. Para isso, mostram-se a atual estrutura de financiamento da educação brasileira e seus principais problemas e os dados do gasto público na área de educação no período de 1995 a 2002. Além disso, apresentam-se dados e indicadores de financiamento e gasto público na área de educação para o Brasil em comparação com alguns países que participam da OCDE e da América Latina.
\end{abstract}

Palavras-chave: Educação básica. Financiamento da educação. Gasto da educação. Financiamento e gasto comparado.

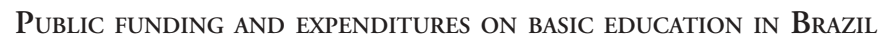
AND COMPARISONS WITH SOME OECD AND LATIN AMERICAN COUNTRIES

ABSTRACT: This paper looks into public funding and expenditures directed to Basic Education in Brazil and some countries of the Organization for Economic Co-operation Development (OCDE) and Latin America, so as to build a comparative situation of expenditures. It thus presents the current funding structure of the Brazilian educational system and its main problems as well as data of public expenditures on education between 1995- 002. Moreover, these data and indicators of public funding and expenditures on education in Brazil are contrasted with those of some OCDE and Latin American countries.

Key words: Basic education. Education funding. Expenditures on education. Educational system.

Doutor em economia pela Universidade Estadual de Campinas (UNICAMP), professor da Universidade de Brasília (UNB) e pesquisador do Instituto de Pesquisa Econômica Aplicada (IPEA) E-mail: jorge.abrahao@ipea.gov.br/jorge.abrahao@globo.com

Educ. Soc., Campinas, vol. 26, n. 92, p. 841-858, Especial - Out. 2005 
Financiamento e gasto público da educação básica no Brasil...

\section{Introdução}

7 educação, ao situar-se no âmbito das responsabilidades do Poder Público, compondo o núcleo central dos atuais sistemas de bemestar social, absorve quantidade expressiva de recursos públicos. Esses recursos, ao darem as principais condiçōes materiais para viabilizar a formulação e implementação das políticas educacionais, podem ser um limite, um obstáculo intransponível ao atendimento das necessidades e demandas por educação. Ressalta-se que o financiamento e o gasto com educação no país também são realizados pelas empresas e pelas famílias, no entanto esse item não será tratado neste trabalho.

Em momentos como o atual, no qual se discute a necessidade de ampliação do acesso à educação e a melhoria da qualidade dos níveis de ensino, bem como mudanças na estrutura de financiamento da educação básica, com inevitáveis impactos de longo prazo para a área, é importante identificar e compreender como se molda o financiamento e o gasto realizado pelo Poder Público para gerar os bens e serviços educacionais, com o fim de aferir possíveis dificuldades a serem enfrentadas. Além disso, a comparação entre países pode ser elemento importante para balizar o desenho e a implementação de políticas para a educaçáo. É, portanto, a partir desta preocupação que este trabalho apresenta uma série de dados e informações sobre o financiamento da educação básica.

Na primeira parte, apresenta-se a atual estrutura de financiamento da educação e seus principais problemas. Na segunda parte elaborou-se o diagnóstico dos gastos públicos na área de educação para o Brasil, no período de 1995 a 2002, formando alguns resultados em termos de indicadores e análises. Em seguida, apresenta-se alguns indicadores de financiamento e gasto público na área de educação para o Brasil em comparação com alguns países que participam da Organização para Cooperação e Desenvolvimento Econômico (OCDE) e da América Latina.

\section{Financiamento público da educação básica no Brasil}

A educação pública, de acordo com as normas legais vigentes, deve ser realizada pela União, pelos estados, pelo Distrito Federal e pelos municípios, que têm a responsabilidade e competência pela manutenção e expansão de três sistemas de ensino. Para viabilizar os gastos com esses sistemas, foi estabelecida uma estrutura de financiamento correspondente. 
Neste sentido, a União deve aplicar recursos na execução de alguns programas/ações próprios, além de poder transferir recursos para os sistemas estaduais e municipais. $\mathrm{Na}$ composição de suas receitas, os estados somam os recursos recebidos da União aos provenientes de suas fontes, os quais são utilizados na manutenção e expansão de seus sistemas de ensino. Por sua vez, na composição dos recursos destinados à manutenção e expansão de suas redes de ensino, os municípios recebem recursos da União e dos estados, os quais são somados a seus recursos próprios. Ou seja, se seguido o estabelecido pela norma legal, o regime de financiamento entre os entes federados deve se pautar pela colaboração, além do que a ação supletiva e redistributiva da União e dos estados está condicionada à plena capacidade de atendimento e ao esforço fiscal de estados, do Distrito Federal e dos municípios.

A estrutura de financiamento da educação é fortemente baseada em impostos, que são recursos gerais tomados à sociedade. Isso significa que parcela expressiva dos recursos, principalmente de estados, Distrito Federal e municípios, é proveniente da arrecadação tributária, sobretudo em razão da vinculação de impostos. Essa forma de financiamento para a educação - reserva de determinado porcentual do valor arrecadado mediante impostos - tem sido uma das medidas políticas mais importantes para garantir a disponibilidade de recursos para o cumprimento do vasto rol de responsabilidades do Poder Público nessa área. Neste sentido, a área de educação historicamente conviveu com um preceito constitucional com este teor, tanto que a Constituição Federal (CF) de 1988 aprovou alguns artigos em defesa dos recursos reservados à educação pública.

Nesta mesma tendência, a Emenda Constitucional que criou o Fundo de Manutenção e Desenvolvimento do Ensino Fundamental e de Valorização do Magistério (FUNDEF) reafirmou a necessidade dos estados, do DF e dos municípios de cumprirem os dispositivos da Constituição de 1988 relativos à vinculação de $25 \%$ de suas receitas de impostos, e daqueles recursos que lhes forem transferidos automaticamente, para a manutenção e o desenvolvimento do ensino, além de obrigar esses entes federados, a partir de 1998, a alocarem $60 \%$ desses recursos no ensino fundamental, ao estabelecer a subvinculação de $15 \%$ daquelas receitas para esse nível de ensino.

Outra fonte de fundamental importância é o salário-educação, criado em 1964 e diretamente destinado ao ensino fundamental, que foi 
Financiamento e gasto público da educação básica no Brasil...

reafirmado pela CF de 1988. Assim, o seu parágrafo 5º, do art. 212, estabelece que "o ensino fundamental público terá como fonte adicional de financiamento a contribuição social do salário-educação, recolhida, na forma da lei, pelas empresas que dela poderão deduzir a aplicação realizada no ensino fundamental de seus empregados e dependentes".

No caso do financiamento das ações do Ministério da Educação (MEC), uma parte dos recursos também pode provir das contribuiçôes sociais, principalmente das contribuiçôes originalmente destinadas ao financiamento da seguridade social. Esses recursos são as fontes de financiamento dos programas como a merenda escolar. A partir de 2002, uma parcela de recursos também passou a ser alocada pelo Fundo de Combate e Erradicação da Pobreza. Uma outra parte provém de operações de crédito com agências internacionais e, também, de outras fontes das quais entram desde aplicações financeiras do Fundo Nacional de Desenvolvimento da Educação (FNDE) até recursos diretamente arrecadados pelas instituiçõoes vinculadas.

Essa estrutura de financiamento em suas características, principalmente após o FUNDEF, acaba por beneficiar sobremaneira as açôes voltadas ao ensino fundamental - não há como se esquecer de que esse nível de ensino foi escolhido como objeto central da política de governo no período de 1995 a 2002. Em contrapartida, para a educação infantil e o ensino médio a atual estrutura de financiamento restringe bastante o poder de dispêndio e, conseqüentemente, as possibilidades de ampliação do acesso e de maior abrangência e qualidade. A primeira restrição e de maior peso diz respeito ao FUNDEF, que não incluiu entre os seus beneficiários os alunos desses níveis de educação, voltando-se exclusivamente ao financiamento do ensino fundamental, considerado prioritário pelo governo federal na segunda metade da década de 1990 . A segunda restrição e de mais longa data diz respeito ao salário-educação, que é destinado de forma explícita e exclusiva ao ensino fundamental.

Além disso, o governo federal tem sido criticado por estar contribuindo cada vez menos na composição dos recursos do FUNDEF. Se, em 1998, a complementação da União correspondia a 3,2\% dos recursos desse Fundo; em 2002, esse índice havia sido reduzido a 2,3\% do total. Esse declínio na participação da União tem sido atribuído ao bai- 
xo ajustamento do gasto mínimo per capita que, desde a sua implantação, não só deixou de cumprir o que estabelecia a própria legislação de regulamentação do Fundo como também não acompanhou o crescimento da arrecadação de estados e municípios. A redução relativa da participação do governo federal na composição do FUNDEF configurou, para alguns, uma forma de desobrigação do Ministério para com o ensino fundamental. Em razão disso, estima-se a necessidade de uma correção expressiva do valor mínimo, o que implicará um aporte significativo de recursos por parte do MEC.

Diante desses problemas, a instituição de um Fundo de Manutenção e Desenvolvimento da Educação Básica e de Valorização dos Profissionais da Educação (FUNDEB) constitui-se em uma reivindicação de parte dos atores sociais ligados à área de educação, principalmente daqueles segmentos vinculados à educação infantil e ao ensino médio. Essa proposta foi parcialmente encampada pelo MEC, que excluiu as creches. Um dos principais óbices à concretização da idéia de incorporação da educação básica completa (educação infantil - incluindo as creches, ensino fundamental e ensino médio) encontra-se na disponibilidade de recursos financeiros necessários à sua implementação. Algumas simulações realizadas indicam que o financiamento do Fundo completo dependerá dos cenários que venham a ser configurados com relação ao gasto aluno/ano mínimo que se adote. Por exemplo, em um cenário de manutenção das estruturas de gasto atuais - gasto aluno/ano esperado para o FUNDEF -, estimou-se que o FUNDEB deveria contar com cerca de $3,4 \%$ do PIB, em 2003, com a complementação da União chegando a 0,09\% do PIB, que é igual ao valor já aplicado (cf. Tabela 1). Porém, sob um cenário de amplas melhorias, os recursos do Fundo deveriam ser de 5,09\% do PIB e a complementação, de 1,73\% do PIB, porcentuais esses maiores que o orçamento atual do Ministério (Castro, 2004, p. 7).

Em contrapartida, os resultados das estimativas mostram que o FUNDEB, assim como o FUNDEF, pode representar no interior de cada estado uma minirreforma tributária, capaz de gerar impasses e forçar negociaçôes entre dirigentes dos executivos estaduais mais atingidos e dirigentes do MEC, visando à cobertura das perdas de recursos estaduais mediante a alocação de recursos federais. No conjunto, observa-se que em todas as regiōes devem ocorrer movimentos nas duas direçôes, predominando, en- 
Financiamento e gasto público da educação básica no Brasil...

tretanto, o processo de descentralização de recursos dos estados para os municípios, não ocorrendo assim processo de centralização. Além disso, a instituição do FUNDEB demandará grande quantidade de recursos para fazer face à complementação da União, o que favorece a consolidação de um volume razoável de recursos para a educação básica.

Portanto, um dos requisitos para que não haja solução de continuidade no processo de universalização da educação básica com qualidade se refere ao equacionamento da questão do financiamento, principalmente a constituição do fundo amplo para a educação básica (incluindo as creches), e a conseqüente ampliação dos recursos públicos para a área; o cumprimento do valor mínimo por aluno, a ser estabelecido para o FUNDEB e a definição do custo aluno/qualidade.

\section{Gasto público na educação básica brasileira}

A investigação dos gastos públicos na educação tem como objetivo compreender o valor (quanto?) e o uso (para quê? Como?) dos recursos colocados à disposição do Poder Público para gerar o bem-estar social, mediante a oferta de bens e serviços educacionais para a população. Para tanto, vai-se utilizar para compor os gastos da educação o conceito de área de atuação na orientação de agrupamento das despesas, formando a área de educação. ${ }^{1}$ Por meio desse conceito, o gasto público é alocado segundo o critério da finalidade ou do objetivo finalístico da despesa, como forma de visualizar as metas e diretrizes delineadas a partir da ação governamental (cf. Fernandes et al., 1998, p. 10; Castro et al., 2003, p. 11).

Tomou-se como período a ser investigado os anos de 1995 a 2002, que retratam o período pós-Plano Real, no qual não ocorreram mudanças de moeda, o que torna os dados mais confiáveis para serem analisados, principalmente em comparaçōes entre exercícios distintos. Foi necessária a estimação dos gastos para os anos de 2000 até 2002. ${ }^{2}$ Além disso, os dados são apresentados em sua representação econômica, o que permite analisar a importância dessa área social no contexto da economia. Para tanto, utilizou-se a relação entre o gasto ocorrido na área de educação e o valor do Produto Interno Bruto (PIB). Está-se admitindo que o PIB é similar ao Gross Domestic Product (GDP), que se denota como PIB @ GDP ou vice-versa. Mediante essas precauçôes, foi possível construir os dados e indicadores que serão apresentados a seguir: 


\section{Tabela 1}

Gasto público na área de educação e gasto público social (1995-2002)

\begin{tabular}{|c|c|c|c|c|c|c|c|c|}
\hline \multirow[t]{3}{*}{ Ano } & \multicolumn{4}{|c|}{ Gasto público na área de educação } & \multirow{3}{*}{$\begin{array}{c}\text { Gasto público } \\
\text { social } \\
\text { (em \% PIB) } \\
\text { (c) }\end{array}$} & \multirow[b]{3}{*}{$(\mathrm{a} / \mathrm{b})$} & \multirow[b]{3}{*}{$(\mathrm{a} / \mathrm{c})$} & \multirow[b]{3}{*}{ (b/c) } \\
\hline & \multicolumn{2}{|c|}{ Educação básica } & \multicolumn{2}{|c|}{ Total } & & & & \\
\hline & (R \$ milhōes) & $\begin{array}{c}\text { (em \% PIB) } \\
\text { (a) }\end{array}$ & (R\$ milhōes) & $\begin{array}{c}\text { (em \% PIB) } \\
\text { (b) }\end{array}$ & & & & \\
\hline 1995 & 20.116 & 3,11 & 25.199 & 3,90 & 20,73 & $80 \%$ & $15 \%$ & $19 \%$ \\
\hline 1996 & 24.420 & 3,14 & 29.670 & 3,81 & 20,90 & $82 \%$ & $15 \%$ & $18 \%$ \\
\hline 1997 & 24.897 & 2,86 & 32.502 & 3,73 & 21,34 & $77 \%$ & $13 \%$ & $17 \%$ \\
\hline 1998 & 30.868 & 3,38 & 38.745 & 4,24 & 22,01 & $80 \%$ & $15 \%$ & $19 \%$ \\
\hline 1999 & 32.629 & 3,35 & 41.475 & 4,26 & 22,32 & $79 \%$ & $15 \%$ & $19 \%$ \\
\hline 2000 & 36.969 & 3,36 & 46.990 & 4,27 & 22,59 & $79 \%$ & $15 \%$ & $19 \%$ \\
\hline 2001 & 40.676 & 3,39 & 51.584 & 4,30 & 22,91 & $78 \%$ & $15 \%$ & $19 \%$ \\
\hline 2002 & 45.765 & 3,39 & 57.943 & 4,30 & 22,90 & $79 \%$ & $15 \%$ & $19 \%$ \\
\hline
\end{tabular}

Fonte: Almeida (2001), IPEA/DISOC, IBGE/MP, INEP/MEC.

Observação: Os dados originais para os gastos públicos em educação (em todos os níveis e modalidades) de 1995 até 1999 foram obtidos de Almeida (2001); já os gastos de 2000 a 2002 representam projeçóes efetuadas pelo autor, com base nos resultados apresentados pela Secretaria do Tesouro Nacional (STN) para a Lei de Responsabilidade Fiscal (LRF), e na dinâmica da arrecadação tributária do período. Elaboração: J. A. Castro.

Os dados da Tabela 1 mostram que os gastos em educação, pelas três esferas de governo, tiveram uma ampliação e ganho de importância, em termos relativos, no período transcorrido de 1995 a 2002, quando saíram de 3,90\% para 4,31\% do PIB (@ GDP). No entanto, observam-se dois movimentos: um entre 1995 e 1997, no qual se pode observar uma queda constante da participação relativa, caindo de $3,90 \%$ para $3,73 \%$ do PIB. Esse movimento pode ser explicado pelo fato de o PIB nesse período ter crescido mais rapidamente que os gastos em educação. Isso significa que a área de educação não foi beneficiada por um maior aporte de recursos quando ocorreu crescimento; em contrapartida, no outro movimento, ocorrido nos dois anos seguintes, momento em que o crescimento foi bastante reduzido, observa-se uma melhoria no valor do indicador $(4,24 \%$ e $4,30 \%$ do PIB). Por esses dados, observa-se que a área foi ampliando seu espaço em termos relativos, principalmente a partir de 1998, coincidentemente, ano da implantação do FUNDEF, quando a importância relativa sobe em cerca de $0,5 \%$ do PIB e se mantém neste patamar nos anos posteriores. No entanto, cabe observar que esses números podem também estar refletin- 
Financiamento e gasto público da educação básica no Brasil...

do um efeito composição, em razão de a taxa do PIB ter sido baixa, embora sinalize que a área conseguiu manter o patamar que tinha.

A educação básica - como mostram os dados - é a subárea da educação que mais absorve recursos, uma vez que no período lhe foram destinados constantemente cerca de $80 \%$ dos recursos disponíveis pelos sistemas. Até por isso, observa-se que grande parte do incremento de recursos se deu nessa subárea.

A comparação entre o gasto público em educação e o gasto social faz-se mister para mostrar o peso da área educacional no esforço público em realizar a proteção social. Neste sentido, os dados comprovam a importância da área, que reteve de forma constante cerca de 19\% do gasto social das três esferas de governo, o que permite afirmar que essa área junto com a previdência social e a saúde compóem os pilares da ação social do Estado no Brasil. Além disso, os dados mostram que a educação básica é o núcleo de gasto da ação educacional do Estado $(15,0 \%$ do gasto social).

Outro indicador da ação do Estado na área educacional é aquele que permite traçar o panorama dos gastos nos principais níveis e mo-

\section{Tabela 2}

Gasto público em educação por nível de ensino e modalidade de educação

(1995-2002)

\begin{tabular}{|c|c|c|c|c|c|c|c|c|c|}
\hline \multirow{3}{*}{ Anos } & & & & & & Em re & ç̧ão a & PIB & \\
\hline & \multicolumn{5}{|c|}{ Níveis e modalidades educacionais } & \multicolumn{4}{|c|}{ Relaçóes (em \%) } \\
\hline & $\begin{array}{c}\text { Educação } \\
\text { infantil } \\
\text { (a) }\end{array}$ & $\begin{array}{l}\text { Ensino } \\
\text { fundamental } \\
\text { (b) }\end{array}$ & $\begin{array}{l}\text { Ensino } \\
\text { médio } \\
\text { (c) }\end{array}$ & $\begin{array}{c}\text { Educação } \\
\text { superior } \\
\text { (d) }\end{array}$ & $\begin{array}{l}\text { Total } \\
\text { (e) }\end{array}$ & $(\mathrm{a} / \mathrm{e})$ & $(\mathrm{b} / \mathrm{e})$ & (c/e) & $(\mathrm{d} / \mathrm{e})$ \\
\hline 1995 & 0,43 & 2,31 & 0,37 & 0,79 & 3,90 & 11 & 59 & 9 & 20 \\
\hline 1996 & 0,42 & 2,33 & 0,39 & 0,67 & 3,81 & 11 & 61 & 10 & 18 \\
\hline 1997 & 0,40 & 2,04 & 0,42 & 0,87 & 3,73 & 11 & 55 & 11 & 23 \\
\hline 1998 & 0,38 & 2,53 & 0,47 & 0,86 & 4,24 & 9 & 60 & 11 & 20 \\
\hline 1999 & 0,39 & 2,48 & 0,47 & 0,91 & 4,26 & 9 & 58 & 11 & 21 \\
\hline 2000 & 0,39 & 2,50 & 0,47 & 0,91 & 4,27 & 9 & 59 & 11 & 21 \\
\hline 2001 & 0,39 & 2,53 & 0,47 & 0,91 & 4,30 & 9 & 59 & 11 & 21 \\
\hline 2002 & 0,39 & 2,53 & 0,48 & 0,90 & 4,30 & 9 & 59 & 11 & 21 \\
\hline
\end{tabular}

Fonte: Almeida (2001), IPEA/DISOC, IBGE/MP, INEP/MEC.

Observação: Os dados originais para os gastos públicos em educação (em todos os níveis e modalidades) de 1995 até 1999 foram obtidos de Almeida (2001); já os gastos de 2000 a 2002 representam projeções efetuadas pelo autor, com base nos resultados apresentados pela Secretaria do Tesouro Nacional (STN) para a Lei de Responsabilidade Fiscal (LRF), e na dinâmica da arrecadação tributária do período. Elaboração: J. A. Castro. 
dalidades de educação desenvolvida (Tabela 2). A distribuição dos gastos é influenciada principalmente pelo número de estudantes envolvido em cada nível ou ação de governo, que por sua vez é influenciado pela duração de cada nível e pela complexidade do aparato (recursos humanos, físicos etc.) necessário à prestação desse serviço público.

O esforço público na área de educação pode ser compreendido segundo uma ordem de importância de gasto. Inicialmente, encontra-se o ensino fundamental, para qual foi destinado grande parte dos recursos, cerca de $60 \%$, e que apresentou crescimento de quase 0,22 pontos porcentuais (p.p.) do PIB, refletindo as prioridades que lhe foram atribuídas pela política pública desenvolvida no período. Em seguida, a educação superior, que absorveu $20 \%$ dos gastos na área e que também teve crescimento (0,11 p.p. do PIB). No caso da educação infantil, percebeu-se um quadro de deslocamento que apresentou sua perda - passou de $11 \%$ para $9 \%$ do gasto em educação -, o que significou uma perda de recursos (0,04 p.p. do PIB). Enquanto isso, o ensino médio vê crescer sua importância, de $9 \%$ para $11 \%$, além da ampliação dos recursos (0,11 p.p. do PIB).

Em contrapartida, o nível de gasto também pode ser um elemento importante para se comparar o grau de responsabilidade pela oferta dos bens e serviços educacionais pelas esferas de governo. A Tabela 3, a seguir, procura mostrar essas evidências apenas para a educação básica.

Os valores dos gastos apresentados na Tabela 3 mostram que a distribuição intergovernamental dos gastos da educação básica é correspondente à vinculação e subvinculação dos recursos destinados à educação, revelando o caráter descentralizado das ações governamentais da área, uma vez que os grandes responsáveis por esta são os estados e municípios, os quais, em conjunto, responderam por $97 \%$ dos gastos da subárea; isso significa que esses governos destinaram aproximadamente $20 \%$ de seus gastos diretos à educação.

Além disso, os dados indicam que a manutenção do volume de gastos em favor da educação foi em larga escala de responsabilidade contínua dos municípios, observando-se, assim, uma forte ampliação deste encargo. Neste sentido, no período analisado os municípios ampliaram sua participação relativa de $38 \%$ para $54 \%$, demonstrando que houve uma municipalização ainda maior neste ínterim. Em contrapartida, os estados reduziram sua participação, de $56 \%$ para cerca de $43 \%$. Enquanto isso, a União continua apresentando baixa participação: demonstrou, inclusive, queda de $5 \%$ para apenas $3 \%$. 
Financiamento e gasto público da educação básica no Brasil...

\section{Tabela 3}

Gasto público em educação básica por esfera de governo (1995-2002)

Em porcentual do PIB

\begin{tabular}{|c|c|c|c|c|c|c|c|}
\hline \multirow{2}{*}{ Ano } & \multicolumn{3}{|c|}{ Unidade Federada } & \multicolumn{2}{|c|}{ Total } & \multicolumn{3}{|c|}{ Relaçōes (\%) } \\
\cline { 2 - 3 } & Municípios & Estados e DF & União & & & & \\
& (a) & (b) & (c) & (d) & (a/d) & (b/d) & (c/d) \\
\hline 1995 & 1,19 & 1,75 & 0,17 & 3,11 & 38 & 56 & 5 \\
1996 & 1,18 & 1,83 & 0,12 & 3,14 & 38 & 58 & 4 \\
1997 & 1,24 & 1,51 & 0,10 & 2,86 & 43 & 53 & 4 \\
1998 & 1,52 & 1,71 & 0,15 & 3,38 & 45 & 51 & 4 \\
1999 & 1,64 & 1,60 & 0,11 & 3,35 & 49 & 48 & 3 \\
2000 & 1,78 & 1,46 & 0,11 & 3,36 & 53 & 44 & 3 \\
2001 & 1,83 & 1,45 & 0,11 & 3,39 & 54 & 43 & 3 \\
2002 & 1,83 & 1,46 & 0,11 & 3,40 & 54 & 43 & 3 \\
\hline
\end{tabular}

Fonte: Almeida (2001), IPEA/DISOC, IBGE/MP, INEP/MEC.

Observação: Os dados originais para os gastos públicos em educação (em todos os níveis e modalidades) de 1995 até 1999 foram obtidos de Almeida (2001); já os gastos de 2000 a 2002 representam projeções efetuadas pelo autor, com base nos resultados apresentados pela Secretaria do Tesouro Nacional (STN) para a Lei de Responsabilidade Fiscal (LRF), e na dinâmica da arrecadação tributária do período. Elaboração: J. A. Castro.

Isso decorre do fato de a atual Constituição Federal brasileira atribuir aos estados e municípios a responsabilidade pela oferta da educação básica, cabendo ao governo federal apenas a função supletiva; assim, a maior parte dos recursos aplicados pelo governo federal, na área da educação, destina-se ao custeio das instituições federais de ensino superior (IFES), escolas técnicas federais e centros federais de ensino tecnológico (CEFET).

\section{Financiamento e gasto público da educação básica em países selecionados}

As principais instituiçõos internacionais que formalizam e comparam dados e indicadores ${ }^{3}$ educacionais e sociais, tais como a OCDE e a Organização das Nações Unidas para a Educação, a Ciência e a Cultura (UNESCO), utilizam o gasto público de cada país na área de educação em 
porcentagem do Gross Domestic Product (GDP) como um indicador da importância relativa dada à educação diante da atividade econômica dos países. Salienta-se que se está admitindo que o Gross Domestic Product (GDP) é similar ao PIB, (GDP @ PIB). Além disso, é importante comparar dados e indicadores de gastos por níveis e modalidades educacionais, quando então se fazem necessárias adaptações metodológicas. ${ }^{4}$ As variações nos valores percentuais refletem diferenças entre os países no que diz respeito ao grau de responsabilidade e compromisso com a educação.

Analisando o gasto na área de educação para o Brasil levando em consideração o comportamento do GDP (que é apresentado na Tabela 3, observa-se que os gastos corresponderam, em 1995, a cerca de 3,9\% do GDP e demonstraram um aumento para cerca de 4,3\%. Esse crescimento significou uma ampliação do esforço do Poder Público destinado à área. No entanto, mesmo com o crescimento dos recursos, quando comparado esse resultado com os exibidos pelos países da OCDE, observa-se que o Brasil, mesmo sendo a $14^{\mathrm{a}}$ economia do mundo, ainda está bem abaixo do esforço médio de todos os países da OCDE (5,3\% do GDP). Ou seja, o Brasil para atingir o esforço público desses países deveria aplicar no mínimo mais $1 \%$ de seu GDP.

Para chegar próximo dos índices apresentados por alguns países do norte da Europa, como Dinamarca $(8,5 \%)$ e Suécia $(7,3 \%)$, o Brasil deveria aplicar a mais entre 4,2\% e 3,0\% do GDP, o que significa quase dobrar os gastos atuais. Mesmo quando se compara esse resultado com os de alguns países da América Latina, observa-se que o Brasil se situa abaixo de Argentina (4,8\%), Chile $(4,4 \%)$ e Paraguai (4,5\%), superando apenas Peru e Uruguai (3,1\%).

Já a magnitude do gasto de cada país em educação com relação ao gasto público total é um indicador da importância relativa dada à área diante das diversas atividades governamentais, sejam econômicas ou em outras áreas sociais. As variaçôes nas participações nesse indicador refletem diferenças entre os países na divisão da responsabilidade no financiamento da educação entre o setor público e o setor privado. Em alguns países, o recurso público é responsável por grande parte dos gastos em educação; ao passo que em outros o setor privado tem maior responsabilidade.

No caso do Brasil, o gasto público efetuado pelas três esferas de governo na área de educação, em 2001, representou cerca de $12 \%$ do 
Financiamento e gasto público da educação básica no Brasil...

\section{Tabela 4}

Gasto público total em educação em comparação com o gasto público total e o GDP $(1995 / 2001)$

\begin{tabular}{|c|c|c|c|c|c|c|c|c|}
\hline \multirow[t]{3}{*}{ Países } & \multicolumn{4}{|c|}{$\begin{array}{c}\text { Gasto público em educação em porcentual do } \\
\text { gasto público total }\end{array}$} & \multicolumn{4}{|c|}{$\begin{array}{c}\text { Gasto público em educação }{ }^{1} \text { em porcentual } \\
\text { do GDP }\end{array}$} \\
\hline & \multicolumn{3}{|c|}{2001} & \multirow{2}{*}{\begin{tabular}{|c|}
1995 \\
$\begin{array}{c}\text { Todos os } \\
\text { níveis }\end{array}$ \\
educacionais
\end{tabular}} & \multicolumn{3}{|c|}{2001} & \multirow{2}{*}{\begin{tabular}{|c|}
1995 \\
$\begin{array}{c}\text { Todos os } \\
\text { níveis } \\
\text { educacionais }\end{array}$
\end{tabular}} \\
\hline & $\begin{array}{c}\text { Primário, } \\
\text { secundário e } \\
\text { pós-secundário }\end{array}$ & $\begin{array}{l}\text { Terciario }^{1} \\
\text { (educaçāo } \\
\text { superior) }\end{array}$ & $\begin{array}{c}\text { Todos os } \\
\text { níveis } \\
\text { educacionais }\end{array}$ & & $\begin{array}{c}\text { Primário, } \\
\text { secundário e } \\
\text { pós- } \\
\text { secundário }^{1}\end{array}$ & $\begin{array}{l}\text { Terciario } \\
\text { (educação } \\
\text { superior) }\end{array}$ & $\begin{array}{c}\text { Todos os } \\
\text { níveis } \\
\text { educacionais }\end{array}$ & \\
\hline Brasil $^{5}$ & 8,3 & 2,7 & 12,0 & m & 3,4 & 0,9 & 4,3 & 3,9 \\
\hline \multicolumn{9}{|c|}{ Países da OCDE selecionados } \\
\hline Austrália & 10,8 & 3,4 & 14,4 & 13,6 & 3,8 & 1,2 & 5,0 & 5,2 \\
\hline Áustria & 7,3 & 2,6 & 11,1 & 10,7 & 3,8 & 1,4 & 5,8 & 6,2 \\
\hline Dinamarca $^{4}$ & 8,7 & 4,9 & 15,4 & 12,7 & 4,8 & 2,7 & 8,5 & 7,7 \\
\hline França & 7,9 & 2,0 & 11,2 & 11,3 & 4,0 & 1,0 & 5,7 & 6,0 \\
\hline Alemanha & 6,4 & 2,4 & 9,7 & 9,7 & 3,0 & 1,1 & 4,6 & 4,6 \\
\hline Itália & 7,6 & 1,7 & 10,3 & 9,1 & 3,7 & 0,8 & 5,0 & 4,9 \\
\hline Corea & 12,8 & 1,7 & 17,7 & $\mathrm{~m}$ & 3,5 & 0,5 & 4,9 & $\mathrm{~m}$ \\
\hline México & 18,0 & 3,5 & 24,3 & 22,4 & 3,8 & 0,7 & 5,1 & 4,6 \\
\hline Portugal & 9,3 & 2,3 & 12,7 & 11,9 & 4,3 & 1,1 & 5,9 & 5,4 \\
\hline Espanha & 7,6 & 2,6 & 11,3 & 10,6 & 3,0 & 1,0 & 4,4 & 4,7 \\
\hline Suíça & 8,4 & 3,6 & 12,8 & 10,6 & 4,8 & 2,0 & 7,3 & 7,2 \\
\hline Reino Unido & 8,4 & 2,0 & 11,4 & 11,4 & 3,4 & 0,8 & 4,7 & 5,2 \\
\hline Estados Unidos ${ }^{3}$ & 11,5 & 4,5 & 17,1 & $\mathrm{~m}$ & 3,8 & 1,5 & 5,6 & $\mathrm{~m}$ \\
\hline Média dos países da CDE & 8,9 & 2,8 & 12,7 & 11,8 & 3,6 & 1,3 & 5,3 & 5,3 \\
\hline \multicolumn{9}{|c|}{ Países da América Latina selecionados } \\
\hline Argentina & 10,1 & 2,3 & 13,5 & $\mathrm{~m}$ & 3,6 & 0,8 & 4,8 & $\mathrm{~m}$ \\
\hline Chile $^{6}$ & 14,5 & 2,6 & 18,7 & $\mathrm{~m}$ & 3,4 & 0,6 & 4,4 & $\mathrm{~m}$ \\
\hline Paraguai & 8,0 & 1,7 & 9,7 & $\mathrm{~m}$ & 3,7 & 0,8 & 4,5 & $\mathrm{~m}$ \\
\hline Peru & 16,1 & 5,3 & 23,5 & $\mathrm{~m}$ & 2,0 & 0,7 & 2,9 & $\mathrm{~m}$ \\
\hline Uruguai & 8,9 & 2,7 & 12,8 & $\mathrm{~m}$ & 2,2 & 0,7 & 3,1 & $\mathrm{~m}$ \\
\hline
\end{tabular}

Fonte: OCDE. Disponível em: <www.oecd.org/edu/eag2004>.

1. As classificações de níveis e modalidades educacionais utilizados seguem a proposta desenvolvida pela UNESCO e que foi construída mediante a International Standard Classification of Education (ISCED) 2. O gasto público apresentado nesta tabela inclui subsídios públicos aos estudantes e que não são efetuados em instituições educacionais.

3. Pós-secundário está incluído no terciário (educação superior) e exclui primário, secundário e póssecundário não-terciário.

4. Pós-secundário está incluído no secundário e na educação superior.

5. Refere-se ao ano de 2000.

6. Refere-se ao ano de 2002.

Elaboração: J. A. Castro. 
gasto total (Tabela 3). Esse mesmo indicador para os países da OCDE foi em média de $12,7 \%$, o que representou no período de 1995 a 2001 uma ampliação de $1 \%$. Ou seja, o Brasil, para atingir o índice desses países, deveria aplicar no mínimo mais $0,7 \%$ de seu gasto público na área de educação.

Para chegar próximo dos países da OCDE que mais destinam recursos públicos à educação - tais como México (24,3\%), Corea $(17,7 \%)$, EUA $(17,1 \%)$-, o Brasil deveria aplicar mais de $5 \%$ de seu gasto público em educação. Quando se compara o índice do Brasil com o de alguns países da América Latina, observa-se que o Brasil se situa abaixo de Peru $(23,5 \%)$, Argentina (13,5\%), Chile (18,7\%), superando apenas o Paraguai (9,7\%).

Quando se compara o índice de gasto referente à educação básica $(8,2 \%)$, observa-se que o Brasil aplica menos nessa etapa da educação do que a média da OCDE $(8,9 \%)$ e menos ainda que grande parte dos países da América Latina. No entanto, a aplicação na educação terciária aproxima-se da média dos países da OCDE e é um pouco superior aos índices dos países da América Latina.

O gasto por aluno/ano - relação entre os recursos financeiros gastos nos níveis e modalidades de educação divididos pelo número de alunos - é outro tipo de indicador bastante útil para comparar países. Esse indicador reflete não apenas quanto da riqueza do país é destinada aos seus estudantes, no sentido de prover educação a cada um deles em cada ano, mas também qual a ênfase de gasto, por nível e modalidade educacional.

Os dados a seguir demonstram que o Brasil, ${ }^{5}$ nos diversos níveis de ensino, gasta por aluno cerca de seis vezes menos que a média dos países da OCDE. Assim, ao passo que os gastos por aluno na educação primária, no Brasil, eram de 832 dólares Purchasing Power Parity (PPP) ${ }^{6}$ em 2001, os Estados da OCDE gastavam em média, nesse mesmo ano, 4.850 dólares PPP por cada estudante da educação primária. A diferença ampliase ainda mais quando se compara o dado relativo à educação secundária (7,5 vezes). Além disso, observa-se baixa variação entre os países europeus, com apenas o México destoando do padrão dos países da OCDE.

Mesmo comparando os dados do Brasil com os de alguns países da América Latina, pode-se perceber que também nesse indicador o gasto por aluno se situa abaixo dos valores realizados por Argentina (2,5 ve- 
Financiamento e gasto público da educação básica no Brasil...

\section{Tabela 5}

Gasto público em educação por aluno/ano e nível educacional (considerando alunos equivalentes em tempo integral) - 2001

Equivalente US dólar convertido usando PPP

\begin{tabular}{|c|c|c|c|c|c|c|}
\hline \multirow[t]{2}{*}{ Países } & \multirow[t]{2}{*}{ Pré-primário ${ }^{1}$} & \multirow{2}{*}{$\begin{array}{c}\text { Ensino } \\
\text { primário } \\
\left(1^{\circ} \text { ciclo }\right. \\
\text { da ed. } \\
\text { básica })^{1}\end{array}$} & \multicolumn{3}{|c|}{ Ensino Segundario $^{1}$} & \multirow{2}{*}{$\begin{array}{l}\text { Pós- } \\
\text { secundario e } \\
\text { não-terciário }\end{array}$} \\
\hline & & & $\begin{array}{l}2^{\circ} \text { ciclo } \\
\text { da ed. } \\
\text { básica }\end{array}$ & $\begin{array}{l}3^{\circ} \text { ciclo } \\
\text { da ed. } \\
\text { básica }\end{array}$ & $\begin{array}{c}\text { Todos os } \\
\text { ciclos do } \\
\text { secundário }\end{array}$ & \\
\hline Brasil $^{2,4}$ & 1.044 & 832 & 862 & 870 & 864 & $\mathrm{~m}$ \\
\hline \multicolumn{7}{|c|}{ Países da OCDE selecionados } \\
\hline Austrália & $\mathrm{m}$ & 5.052 & 7.042 & 7.587 & 7.239 & 6.057 \\
\hline Áustria & 5.713 & 6.571 & 8.316 & 8.852 & 8.562 & 8.240 \\
\hline Dinamarca & 4.542 & 7.572 & 7.653 & 8.531 & 8.113 & $\mathrm{~m}$ \\
\hline França & 4.323 & 4.777 & 7.491 & 8.884 & 8.107 & 6.529 \\
\hline Alemanha & 4.956 & 4.237 & 5.366 & 9.223 & 6.620 & 9.460 \\
\hline Italia $^{2}$ & 5.972 & 6.783 & 8.558 & 8.051 & 8.258 & $\mathrm{~m}$ \\
\hline Corea & 1.913 & 3.714 & 4.612 & 5.681 & 5.159 & $\mathrm{~m}$ \\
\hline México & 1.410 & 1.357 & 1.342 & 3.144 & 1.915 & $\mathrm{~m}$ \\
\hline Portugal & $\mathrm{m}$ & 4.181 & 5.882 & 6.076 & 5.976 & $\mathrm{~m}$ \\
\hline Espanha & 3.608 & 4.168 & $\mathrm{~m}$ & $\mathrm{~m}$ & 5.442 & $\mathrm{~m}$ \\
\hline Suíça & 3.504 & 6.295 & 6.285 & 6.628 & 6.482 & 3.757 \\
\hline Reino Unido & 7.595 & 4.415 & $\mathrm{~m}$ & $\mathrm{~m}$ & 5.933 & $\mathrm{~m}$ \\
\hline Estados Unidos ${ }^{3}$ & 8.522 & 7.560 & 8.359 & 9.278 & 8.779 & $\mathrm{~m}$ \\
\hline $\begin{array}{l}\text { Média dos países } \\
\text { OCDE }\end{array}$ & 4.187 & 4.850 & 5.787 & 6.752 & 6.510 & 3.705 \\
\hline \multicolumn{7}{|c|}{ Países da América Latina selecionados } \\
\hline Argentina & 1.745 & 1.655 & 2.189 & 2.487 & 2.306 & $\mathrm{~m}$ \\
\hline Chile $^{5}$ & 1.766 & 2.110 & 2.070 & 2.094 & 2.085 & $\mathrm{~m}$ \\
\hline Paraguai & $x(2)$ & 802 & $\mathrm{~m}$ & $\mathrm{~m}$ & 1.373 & $\mathrm{~m}$ \\
\hline Peru & 359 & 431 & 528 & 547 & 534 & $\mathrm{~m}$ \\
\hline Uruguai $^{2}$ & 1.200 & 1.202 & 889 & 1.243 & 1.046 & $\mathrm{~m}$ \\
\hline
\end{tabular}

Fonte: OCDE. Disponível em: <www.oecd.org/edu/eag2004>.

1. As classificações de níveis e modalidades educacionais utilizados seguem a proposta desenvolvida pela UNESCO e que foi construída mediante a International Standard Classification of Education (ISCED).

2. Terciário (educação superior) e somente gasto em instituiçôes públicas.

3. Somente gasto em instituições públicas e em instituiçóes privadas independentes.

4. Refere-se ao ano de 2000.

5. Refere-se ao ano de 2002.

Elaboração: J. A. Castro. 
zes superior), Chile (2 vezes) e Uruguai, em todos os níveis e modalidades educacionais.

No entanto, é importante alertar que baixos gastos não podem ser automaticamente associados com baixa qualidade da educação oferecida. Entretanto, quando esses números são tão expressivos como os que são apresentados aqui, não há como não se questionar os possíveis resultados que podem advir de um sistema com esse baixo perfil de gasto. Neste sentido, os dados da edição 2003 do Programa Internacional de Avaliação de Alunos (PISA) são extremamente esclarecedores ao mostrar uma relação positiva entre o gasto por aluno e o aproveitamento escolar; com o aumento de gasto por aluno em instituiçôes educacionais há um incremento de desempenho educacional.

\section{Considerações finais}

O sistema de financiamento das políticas de educação manteve sua proteção contra cortes orçamentários, que lhe é típico. No entanto, por dentro sofreu uma reestruturação - principalmente com a criação do FUNDEF, centrado no ensino fundamental - que trouxe dificuldades para o aporte de mais recursos para os outros níveis e modalidades. Por isso, os dados mostram uma queda nos valores aplicados na educação infantil. Além disso, houve transferência crescente das responsabilidades para os municípios, configurando-se um processo de forte municipalização, com os estados e o governo federal perdendo importância. Com isso, o regime de colaboração na prática foi pouco ou nada exercido.

Quanto aos gastos públicos nas políticas de educação, as informações apresentadas revelam que: (i) a educação é bastante importante nos gastos sociais, reafirmando sua posição de constituir-se em um dos pilares da proteção social brasileira; (ii) o caráter descentralizado das ações governamentais da área, com estados e municípios sendo as instâncias federadas que mais se ocupam das ações de educação, respondendo pela maioria dos gastos realizados e comprometendo parcela razoável de seus recursos nãofinanceiros nesta direção; (iii) pouca importância, em termos de recursos aplicados, do governo federal no financiamento da educação básica; (iii) grande esforço de gasto público destina-se ao ensino fundamental, confirmando a prioridade política conferida a esse nível de ensino, seguido dos gastos com a educação superior, o ensino médio e a educação infantil. 
As comparações internacionais mostraram que o Brasil se encontra em uma situação de aplicação de recursos, tanto com relação ao GDP, gasto público e per capita, bem abaixo da maioria dos países da OCDE e até mesmo dos principais países da América Latina. Quadro esse que demonstra que em alguns países é dada grande importância à educação no decorrer da ação pública e que, portanto, se a educação estivesse no centro da agenda política brasileira, a ela deveriam ser destinados mais recursos, para assim se realizar alternativas mais ousadas de ampliação do acesso e melhorar a qualidade de toda a educação básica.

\section{Recebido e aprovado em agosto de 2005.}

\section{Notas}

1. Seguindo a metodologia do Instituto de Pesquisa Econômica e Aplicada (IPEA), para a área de atuação educação, computam-se todas as despesas com formulação da política setorial e a manutenção, expansão e melhoria de escolas de diversos níveis e modalidades de ensino: educação da criança de 0 a 6 anos (educação infantil), ensino fundamental, ensino médio e profissionalizante, ensino superior, ensino supletivo e educação de jovens e adultos, educação especial, educação indígena e educação física e desporto (inclui instituições militares de ensino regular - médio e superior - abertas ao ingresso público, mas exclui aquelas voltadas somente para a formação de servidores civis ou militares), estabelecimentos de educação física e desporto e programas de assistência a estudantes.

2. Salientam-se as limitações da estimação feita por meio da criação de cenários que obviamente não conseguem cobrir todas as especificidades que as variaçôes reais exigiriam. Como em grande parte dos trabalhos do gênero, torna-se necessária a utilização de um certo grau de arbitrariedade para a montagem das projeções para os parâmetros utilizados. Apesar disso, acredita-se estar fornecendo uma medida relativa minimamente aceitável das modificações recentes na estrutura e na responsabilidade da execução dos gastos, sendo mais importante observar a tendência do que os valores propriamente ditos.

3. Esses indicadores foram produzidos a partir do projeto World Education Indicators (WEI), dos quais participam 29 países-membros da OCDE e 14 países convidados, entre eles o Brasil, o qual pela primeira vez participou do projeto WEI, que foi coordenado pelo Instituto Nacional de Estudos e Pesquisas Educacionais Anísio Teixeira (INEP), com a cooperação do IPEA e do Instituto Brasileiro de Geografia e Estatística (IBGE). O projeto deu origem à publicação Education at a glance.

4. As classificações de níveis e modalidades educacionais utilizadas nesta parte do trabalho seguem a proposta desenvolvida pela UNESCO e que foi construída mediante a International Standard Classification of Education (ISCED). Dessa forma, cada país teve conseqüentemente adaptados os dados de gasto de acordo com essa classificação.

5. Os dados de gasto médio para o Brasil só consideram os gastos públicos. Caso fosse considerado o gasto privado, ter-se-ia como conseqüência um aumento no gasto médio, no entanto não seriam suficientes para alterar profundamente esse indicador. Isso porque a ma- 
trícula nos níveis educacionais que estão considerados neste trabalho é, em sua grande maioria, de responsabilidade do Poder Público.

6. Purchasing Power Parity (PPP) refere-se à paridade do poder de compra, porque os dados em dólares não são transladáveis ao cambio corrente.

\section{Referências bibliográficas}

ALMEIDA, I.C. Gastos com educação no período de 1994 a 1999 . Revista Brasileira de Estudos Pedagógicos, Brasília, DF, v. 82, n. 200/201/202, p. 137-198, jan./dez. 2001.

BRASIL. Constituição (1988). Constituição da República Federativa do Brasil. Brasília, DF: Senado, 1988.

BRASIL. Lei no 9.394, de 20 de dezembro de 1996. Estabelece as diretrizes e base da educação nacional. Diário Oficial da União. Brasília, DF, 23 dez. 1996. p. 27894.

BRASIL. Ministério da Educação. Plano Nacional de Educação. Brasília, DF: MEC/INEP, 2001.

CASTRO, J. Financiamento da educação: necessidades e possibilidades. Brasília, DF: IPEA, 2004. (mimeo.).

CASTRO, J.; FERNANDES, M.A. Sistema de informações sobre os gastos públicos da área de educação - SIGPE: diagnóstico para 1995. Texto para Discussão, Brasília, DF, IPEA, n. 674, 1999.

CASTRO, J.; SADECK, F. Financiamento do gasto em educação das três esferas em 2000. Texto para Discussão, Brasília, DF, IPEA, n. 955, 2003.

CASTRO, J. et al. Análise da evolução e dinâmica do gasto social federal: 1995-2001. Texto para Discussão, Brasília, DF, IPEA, n. 988, 2003.

FERNANDES, M.A. Mensuração do gasto público social: a metodologia desenvolvida na Diretoria de Estudos Sociais do IPEA. Brasília, DF: IPEA, 2000. (mimeo.).

FERNANDES, M.A. et al. Dimensionamento e acompanhamento do gasto social federal, 1994-1996. Texto para Discussão, Brasília, DF, IPEA, n. 547, 1998.

INSTITUTO NACIONAL DE ESTUDO DE PESQUISAS EDUCACIONAIS (INEP). Relatório do grupo de trabalho sobre financia- 
Financiamento e gasto público da educação básica no Brasil...

mento da educação. Revista Brasileira de Estudos Pedagógicos, Brasília, DF, v. 82, n. 200/201/202, p. 117-135, jan./dez. 2001.

INSTITUTO NACIONAL DE ESTUDO DE PESQUISAS EDUCACIONAIS (INEP). PISA 2000 Relatório Nacional. Brasília, DF, dez. 2001. Disponível em: <www.inep.gov.br/internacional/pisa>. Acesso em: jul. 2005.

ORGANISATION ECONOMIC CO-OPERATION AND DEVELOPMENT (OCDE). Education at a glance: OCDE - indicators. Paris: OCDE, 2003. Disponível em: <http://www.oecd.org>. Acesso em: jul. 2005.

ORGANISATION ECONOMIC CO-OPERATION AND DEVELOPMENT (OCDE). Education at a glance: OCDE - indicators. Paris: OCDE, 2004. Disponível em: <www.oecd.org/edu/eag2004>. Acesso em: jul. 2005.

ORGANISATION ECONOMIC CO-OPERATION AND DEVELOPMENT (OCDE). PISA 2003: Technical Report. Paris: OCDE, 2005. Disponível em: <www.pisa.oecd.org/document/13/0,2340,en_3225 2351_32236173_35188685_1_1_1_1,00.html>. Acesso em: jul. 2005.

UNITED NATIONS EDUCATIONAL, SCIENTIFIC AND CULTURAL ORGANIZATION (UNESCO). International Standard Classification of Education (ISCED) 1997 [on-line]. Disponível em: <http:// www.uis.unesco.org>. Acesso em: jul. 2005. 